\title{
O outro lado, de Alfred Kubin
}

Simone Pereira Gonçalves

Alfred Leopold Isidor Kubin (1877-1959) nasceu em Leitmeritz, Boêmia, que fazia parte do Império Austro-Húngaro, e faleceu em Zwickledt / Wernstein am Inn, Áustria. Era desenhista, ilustrador e escritor. Participou do movimento expressionista O Cavaleiro Azul [Der Blaue Reiter] e conta entre um dos mais importantes ilustradores do século 20. Kubin escreveu seu primeiro e único romance em apenas três meses, durante uma fase de crise na sua produção artística, e precisou de mais um mês para fazer as ilustrações do romance que, segundo ele, tinham muito mais a dizer do que o próprio texto.

O outro lado [Die andere Seite], publicado em 1909, narra a experiência de um desenhista e ilustrador, o próprio narrador, que se aventura juntamente com sua mulher em uma viagem ao Império dos Sonhos, a convite de um antigo colega de escola, Claus Patera. O convite, a viagem e a estada no Império dos Sonhos, um Estado criado por Patera na Ásia Central, estão encobertos de mistérios. No início da viagem, tem-se a impressão de que os aventureiros vão em busca do melhor dos mundos possíveis; mas, ao longo da viagem, a paisagem vai se tornando mais monótona e o humor do próprio narrador vai se alterando progressivamente. Começa a surgir uma aura estranha, de dúvidas, preocupações, acompanhada de uma certa angústia. A chegada ao Império dos Sonhos indica muito mais a iminência de o pior dos mundos possíveis. 
Muitos críticos referem-se a Kubin como um visionário. Precisamente no momento da chegada ao Império dos Sonhos, parece que se está entrando em um Estado totalitário. Segundo Clemens Ruthner ${ }^{1}$, o romance de Kubin tem um valor paradigmático dentro da tendência internacional de textos utópicos e antiutópicos da virada do século.

O fundador do Império dos Sonhos, Claus Patera, é avesso ao entusiasmo positivista, ao progresso e à ciência, aspecto revelador do pessimismo schopenhauriano, e cria um Estado composto por antigas construções sombrias e sem valor aparente, compradas na Europa e reconstruídas no Império dos Sonhos. Seus habitantes compõem-se de pessoas com "uma sensibilidade extremamente delicada, pessoas com ideias fixas ainda não excessivas, com mania de colecionar, avidez de leitura, vício do jogo, hiper-religiosidade (...)"2

O outro lado tornou-se logo conhecido entre os contemporâneos de Kubin. De acordo com Ruthner, o fato de a influência de Kubin sobre diversos autores, como Franz Kafka, Ernst Jünger e Christoph Ransmayr não ser muito conhecida, deve-se à falta de reconhecimento que a germanística conferiu a esse texto, relegando-o à categoria de literatura alemã fantástica da virada do século. Precisamente o caráter fantástico desse texto é relevante para Ruthner.

Kubin teria ilustrado o romance de Gustav Meyrink, O Golem, mas quando este entrou numa fase de crise e bloqueio, Kubin parou também com o respectivo trabalho e utilizou as onze ilustrações já prontas para o seu próprio romance.

Ruthner interpreta O outro lado como uma alegoria do Estado, contestando a teoria de Tzvetan Todorov sobre a incongruência entre literatura fantástica e alegoria. Mas antes de expor a sua tese, destaca algumas interpretações vigentes na pesquisa sobre a obra de Kubin.

Clemens Ruthner: Traumreich, die fantastische Allegorie der Habsburger Monarchie in Alfred Kubins Roman Die andere Seite (1908/09), em , p. 1.

2 Alfred Kubin: Die andere Seite, Frankfurt am Main: Suhrkamp Verlag, 2009, p. 59-60. 
O texto pode ser lido simplesmente como um romance de aventura exótico, com traços de literatura fantástica, como era comum ao espírito do tempo por volta 1900, a exemplo de autores como Jules Vernes, Karl May, Joseph Conrad, Henry Rider Haggard.

A questão da figura paterna representada pelo personagem Claus Patera - em grego "patera" significa pai - pode ser reconhecida em uma interpretação psicanalítica como um trauma paterno de cunho biográfico.

Outros pesquisadores consideram o romance de Kubin como uma ação narrativa paralela ao discurso da psicanálise daquela época. A viagem ao Império dos Sonhos é vista como uma transposição literária do ato de adormecer, sonhar e acordar, como literarização do trabalho do sonho. O próprio Kubin escreveu em 22 de dezembro de 1914, referindo-se à primeira interpretação psicanalítica do romance: "Na minha opinião a descoberta de Freud é fabulosa, porém permanece presa na materialidade, ou está fadada a permanecer, porque toda a cientificidade racional não pode fornecer mais do que elementos de construção."3

O outro lado também foi recebido como uma alegoria política ou como alegoria do sincretismo filosófico e artístico de Alfred Kubin, baseado na leitura de Arthur Schopenhauer, Julius Bahnsen, Salomon Friedländer, Otto Weininger, religiões asiáticas, etc.

Como alegoria fantástica do Império Austro-Húngaro, o Império dos Sonhos constitui um império colonial imaginado na Ásia Central como alusão à Europa Central, criado na época da última grande expansão imperialista europeia na África e na Ásia, assim como na época da anexação da Bósnia-Herzegovina ao Império Austro-Húngaro. O romance também apresenta uma ação literária paralela ao sionismo. Um território estrangeiro é ocupado simbolicamente e mais tarde colonizado por um grupo de refugiados europeus. O Império dos Sonhos poderia ser visto como apoteose gro-

3 Ruthner, p. 5 (nota de rodapé $\left.n^{\circ} 30\right)$. 
Simone Pereira Gonçalves. O outro lado, de Alfred Kubin

tesca e declínio do Império Austro-Húngaro, como a derrocada de uma Europa Central antiquada através da influência de uma democracia ocidental e sobretudo do capitalismo americano. O pensamento político de Kubin estaria muito próximo daquele apresentado por Thomas Mann em “Considerações de um apolítico". ${ }^{4}$

$4 \quad$ Id, p. 8. 


\section{Die andere Seite}

\section{Erster Teil - Der Ruf}

\section{Erstes Kapitel - Der Besuch}

Unter meinen Jugendbekannten war ein sonderbarer Mensch, dessen Geschichte wohl wert ist, der Vergessenheit entrissen zu werden. Ich habe mein möglichstes getan, um wenigstens einen Teil der seltsamen Vorkommnisse, die sich an den Namen Claus Patera knüpfen, wahrheitsgetreu, wie es sich für einen Augenzeugen gehört, zu schildern.

Dabei ist mir etwas Eigentümliches passiert: während ich gewissenhaft meine Erlebnisse niederschrieb, ist mir unmerklich die Schilderung einiger Szenen untergelaufen, denen ich unmöglich beigewohnt und die ich von keinem Menschen erfahren haben kann. Man wird hören, welcherlei seltsame Phänomene der Einbildungskraft die Nähe Pateras in einem ganzen Gemeinwesen hervorbrachte. Diesem Einfluß muß ich meine rätselhafte Hellsichtigkeit zuschreiben. Wer eine Erklärung sucht, halte sich an die Werke unserer so geistvollen Seelenforscher.

Ich lernte Patera vor sechzig Jahren in Salzburg kennen, als wir beide in das dortige Gymnasium eintraten. Er war damals ein ziemlich kleiner, doch breitschultriger Bursche, bei dem höchstens der schöngelockte Kopf antiken Zuschnittes auffallen konnte. Mein Gott, wir waren damals wilde, lümmelhafte Buben, was gaben wir viel auf Äußerlichkeiten? Trotzdem muß ich erwähnen, daß mir heute noch, als betagtem Mann, recht gut die etwas vorstehenden, übergroßen Augen von hellgrauer Farbe im Gedächtnis geblieben sind. Aber wer dachte denn in jenen Zeiten an das 'Später'?

Nach drei Jahren vertauschte ich das Gymnasium mit einer anderen Lehranstalt, der Verkehr mit meinen ehemaligen Kameraden wurde immer spärlicher, bis ich schließlich von Salzburg fort in eine andere Stadt kam und für viele Jahre alles, was mir dort bekannt war, aus den Augen verlor.

Die Zeit floß dahin und mit ihr meine Jugend, ich hatte so manches Bunte erlebt, war nun schon ein Dreißiger, verheiratet und schlug mich als Zeichner und Illustrator schlecht und recht durchs Leben. 
Da - es war in München, wo wir damals wohnten - wurde mir an einem nebligen Novembernachmittag der Besuch eines Unbekannten gemeldet.

“Eintreten!"

Der Besucher war - soweit ich im Dämmerlichte unterscheiden konnte - ein Mann von Durchschnittsäußerem, der sich hastig vorstellte:

"Franz Gautsch; bitte, kann ich Sie eine halbe Stunde sprechen?"

Ich bejahte, bot dem Herrn einen Stuhl an und ließ Licht und Tee bringen.

“Womit kann ich dienen?"und meine anfängliche Gleichgültigkeit wandelte sich erst in Neugier, dann in Erstaunen, als der Fremde ungefähr nachfolgendes erzählte:

"Ich werde Ihnen einige Vorschläge machen. Ich spreche nicht für mich, sondern im Namen eines Mannes, den Sie vielleicht vergessen haben, der sich Threr aber noch gut erinnert. Dieser Mann ist im Besitze von für europäische Begriffe unerhörten Reichtümern. Ich spreche von Claus Patera, Ihrem ehemaligen Schulkameraden. Bitte, unterbrechen Sie mich nicht! Durch einen eigentümlichen Zufall kam Patera zu dem vielleicht größten Vermögen der Welt. Ihr einstiger Freund ging nun an die Verwirklichung einer Idee, welche allerdings eine gewisse Unerschöpflichkeit der materiellen Mittel zur Voraussetzung hat. - Ein Traumreich sollte gegründet werden! - Der Fall ist kompliziert; ich werde mich kurz fassen.

Zunächst wurde ein geeignetes Areal von dreitausend Quadratkilometern erworben. Ein Drittel dieses Landes ist stark gebirgig, den Rest bilden eine Ebene und Hügelgelände. Große Wälder, ein See und ein Fluß teilen und beleben dieses kleine Reich. Eine Stadt wurde angelegt, Dörfer, Meierhöfe; dazu war sofort ein Bedürfnis vorhanden, denn schon die Anfangsbevölkerung bezifferte sich auf zwölftausend Seelen. Jetzt zählt das Traumreich fünfundsechzigtausend Einwohner."

Der fremde Herr machte eine kleine Pause und nahm einen Schluck Tee. Ich war ganz still und sagte nur ziemlich betreten:

"Weiter!" 
Und ich erfuhr dann folgendes:

"Patera hegt einen außerordentlich tiefen Widerwillen gegen alles Fortschrittliche im allgemeinen. Ich sage nochmals, gegen alles Fortschrittliche, namentlich auf wissenschaftlichem Gebiete. Bitte meine Worte hier möglichst buchstäblich aufzufassen, denn in ihnen liegt der Hauptgedanke des Traumreiches. Das Reich wird durch eine Umfassungsmauer von der Umwelt abgegrenzt und durch starke Werke gegen alle Überfälle geschützt. Ein einziges Tor ermöglicht den Ein- und Austritt und macht die schärfste Kontrolle über Personen und Güter leicht. Im Traumreiche, der Freistätte für die mit der modernen Kultur Unzufriedenen, ist für alle körperlichen Bedürfnisse gesorgt. Der Herr dieses Landes ist weit davon entfernt, eine Utopie, eine Art Zukunftsstaat schaffen zu wollen. Anhaltende materielle Not ist, nebenbei erwähnt, dort ausgeschlossen. Die vornehmsten Ziele dieser Gemeinschaft sind überhaupt weniger auf Erhaltung der realen Werte, der Bevölkerung und Einzelwesen gerichtet. Nein, durchaus nicht!... aber ich sehe Sie ungläubig lächeln, und in der Tat, es ist fast allzu schwer für mich, mit trockenen Worten das zu beschreiben, was Patera mit dem Traumreich eigentlich will.

Zunächst wäre hier zu bemerken, daß jeder Mensch, der bei uns Aufnahme findet, durch Geburt oder ein späteres Schicksal dazu prädestiniert ist. Eminent geschärfte Sinnesorgane befähigen ihre Inhaber bekanntlich zum Erfassen von Beziehungen der individuellen Welt, welche für Durchschnittswesen, abgesehen von vereinzelten Momenten, einfach nicht vorhanden sind. Und sehen Sie, gerade diese sozusagen unvorhandenen Dinge bilden die Hauptessenz unserer Bestrebungen. Im letzten und tiefsten Sinne ist es die unergründliche Weltenbasis, welche die Traumleute - so nennen sie sich - keinen Augenblick außer acht lassen. Normalleben und Traumwelt sind vielleicht Gegensätze, und eben diese Verschiedenheit macht eine Verständigung so schwer. Auf die Frage: was geschieht eigentlich im Traumlande? wie lebt man dort? müßte ich schlechterdings schweigen. Ich könnte Ihnen nur die Oberfläche schildern, aber zum Wesen des Traummenschen gehört es ja gerade, daß er in die Tiefe strebt. Alles ist auf ein möglichst durchgeistigtes Leben angelegt; Leid und Freud der Zeitgenossen sind dem Träumer fremd. Sie müssen ihm von seinem ganz anderen Wertungsmaßstab aus natürlich fremd bleiben. Am ehesten dürfte noch, wenigstens vergleichsweise, der Begriff 
'Stimmung' den Kern unserer Sache treffen. Unsere Leute erleben nur Stimmungen, besser noch, sie leben nur in Stimmungen; alles äußere Sein, das sie durch möglichst ineinandergreifende Zusammenarbeit nach Wunsch gestalten, gibt gewissermaßen nur den Rohstoff. Daß dieser nicht ausgeht, dafür ist selbstverständlich überreichlich gesorgt. Doch glaubt der Träumer an nichts als an den Traum - an seinen Traum. Dieser wird bei uns gehegt und entwickelt, ihn zu stören wäre unausdenkbarer Hochverrat. Darum auch die strenge Sichtung der Personen, die eingeladen werden, an diesem Gemeinwesen teilzunehmen. Um mich kurz zu fassen und zu Ende zu kommen"- hier legte Gautsch seine Zigarette fort und blickte mir ruhig ins Gesicht:

“Claus Patera, absoluter Herr des Traumreichs, beauftragt mich als Agenten, Ihnen die Einladung zur Übersiedelung in sein Land zu überreichen."

Die letzten Worte sprach mein Besucher etwas lauter und sehr förmlich. Und nun schwieg dieser Mensch, und auch ich war vorerst still, was jeder meiner Leser begreifen wird. Fast zwingend hatte sich mir nämlich der Gedanke aufgedrängt, einem Irrsinnigen gegenüber zu sitzen. Es war mir wahrhaftig recht schwer, meine Aufregung zu verbergen. Scheinbar spielend rückte ich die Lampe aus dem unmittelbaren Bereich meines Besuchers, zugleich entfernte ich geschickt einen Zirkel sowie ein kleines Radiermesser - spitze, gefährliche Gegenstände. -

Die ganze Situation war entschieden äußerst peinlich. Beim Anfang der Traumgeschichte hatte ich an einen Scherz gedacht, den sich irgendein Bekannter mit mir erlauben wollte. Leider schwand dieser Hoffnungsschimmer immer mehr, und seit zehn Minuten überlegte ich krampfhaft meine Chancen. Zwar wußte ich, das beste bei Geisteskranken sei immer, auf die fixen Ideen einzugehen. Aber trotzdem! ich bin durchaus kein Riese, ich bin ein schüchterner, ein schwächlicher Mensch im Grunde! Und da sitzt dieser schwere Gautsch, mit korrekter Assessorenphysiognomie, Kneifer und blondem Spitzbart in meinem Zimmer.

So ungefähr waren damals meine Gedanken. Und sagen mußte ich nun auch etwas, mein Gegenüber wartete ja darauf. Bei einem Tobsuchtsanfall konnte ich schlimmstenfalls immer noch die Lampe ausblasen und mich leise aus dem mir wohlbekannten Raume stehlen. 
"Gewiß, gewiß! ich bin begeistert! ich werde nur noch mit meiner Frau Rücksprache nehmen. Morgen, Herr Gautsch, erhalten Sie dann meine Antwort."Ich redete so in begütigendem Tone und erhob mich. Mein Gast blieb aber ganz ruhig sitzen und sagte trocken:

"Sie mißverstehen unsere gegenwärtige Lage, das finde ich begreiflich. Höchst wahrscheinlich schenken Sie mir keinen Glauben, wenn nicht gar Ihre mühsam zurückgehaltene Aufregung auf einen noch ärgeren Verdacht mir gegenüber hindeutet. Ich versichere Sie, ich bin ganz gesund, so gesund wie nur je irgendeiner. Was ich Ihnen mitteilte, ist vollster Ernst; daß es merkwürdig, wunderbar klingt, nun ja, gebe ich gerne zu. Vielleicht werden Sie ruhiger, sobald Sie sich dieses angesehen haben."

Dabei zog er ein kleines Paket hervor und legte es vor mich auf den Tisch. Ich las meine genaue Adresse, erbrach das Siegel und hielt ein glattes Lederetui von graugrüner Farbe in den Händen. Darin befand sich eine kleine Miniature, ein auffallend charakteristisches Brustbild eines jungen Mannes. Braune Locken umringelten ein Antlitz merkwürdig antiker Prägung; groß, überhell, gerade aus dem Bilde heraus, starrten mich die Augen an: - das war unstreitig Claus Patera!... In den zwanzig Jahren, die wir uns nicht mehr gesehen, hatte ich kaum einmal an diesen für mich verschollenen Schulfreund gedacht. Beim Anblick seines sehr ähnlichen Porträts schrumpfte diese beträchtliche Zeitpause in meinem Geist zusammen. Vor mir tauchten die langen, gelbgestrichenen Korridore des Salzburger Gymnasiums auf, ich sah wieder den alten Schuldiener mit dem würdigen Kropf, nur mühsam verdeckt durch eine raffinierte Bartkultur. Ich sah mich wieder, mitten unter den Jungen und mitten drin auch Claus Patera, geschändet durch einen steifen Filzhut, ein Zwangskleidungsstück, dem verworrenen Geschmack seiner Ziehtante entsprungen.

"Woher haben Sie dieses Bild?" rief ich, unwillkürlich von froher, neugieriger Stimmung gepackt. (...) 


\section{O outro lado}

\section{Primeira parte - A chamada \\ Primeiro capítulo - A visita ${ }^{5}$}

Entre os meus conhecidos de juventude havia uma pessoa singular cuja história é bem digna de ser arrancada do esquecimento. Eu fiz o melhor que pude para retratar de modo fidedigno, como é apropriado a uma testemunha ocular, ao menos uma parte dos estranhos acontecimentos vinculados ao nome de Claus Patera.

Nessa ocasião me aconteceu algo inusitado: enquanto eu escrevia acuradamente minhas experiências, ocorreu-me, sem que eu me desse conta, a descrição de algumas cenas as quais é impossível que eu tenha presenciado e que não posso ter sabido por outra pessoa. Se ouvirá sobre os estranhos fenômenos da força da imaginação que a proximidade de Patera produziu em uma comunidade inteira. A esta influência tenho de atribuir minha misteriosa lucidez. Aquele que procura uma explicação atenha-se às obras dos nossos tão perspicazes investigadores da alma.

Conheci Patera há sessenta anos, em Salzburg, quando nós dois entramos para o liceu. Na época, ele era um garoto de estatura bem baixa mas de ombros largos, no qual só podia chamar a atenção a cabeça com cabelos bem cacheados no estilo antigo clássico. Meu Deus, naquela época éramos uns moleques danados e malcriados e não dávamos a menor importância às aparências! Apesar disso, preciso mencionar que ainda hoje enquanto homem idoso guardo bem claro na memória os olhos enormes e um pouco sobressalentes de cor cinza claro. Mas quem é que na época pensava no "depois"?

Três anos mais tarde, mudei do liceu para um outro estabelecimento de ensino e o contato com meus antigos colegas tornou-se cada vez mais escasso até que me fui de Salzburg para uma outra cidade, perdendo de vista por muitos anos tudo o que me era conhecido.

\footnotetext{
5 Páginas 9-15.
} 
O tempo transcorria e com ele a minha juventude. Eu havia passado por muitas experiências, tinha então já meus trinta anos, era casado e me virava mais ou menos na vida como desenhista e ilustrador.

\section{II}

Naquele tempo - era em Munique onde morávamos na época - em uma tarde nebulosa de novembro me foi anunciada a visita de um desconhecido.

- Entre!

A visita era - tanto quanto eu podia distinguir no lusco-fusco - um homem de aparência comum que se apresentou apressadamente:

- Sou Franz Gautsch, posso falar com o senhor por meia hora?

Consenti, oferecendo àquele senhor uma cadeira, e mandei trazer luz e chá.

- Em que posso lhe servir?

E minha indiferença inicial transformou-se primeiramente em curiosidade, depois em assombro quando o estranho contou aproximadamente o seguinte:

- Vou-lhe fazer algumas propostas. Não falo por mim, senão em nome de um homem do qual o senhor talvez tenha-se esquecido, o qual porém se lembra bem do senhor. Este homem possui, para o entendimento europeu, riquezas inauditas. Estou falando de Claus Patera, seu antigo colega de escola. Por favor, não me interrompa! Por uma curiosa casualidade, Patera adquiriu o maior patrimônio do mundo. Seu antigo amigo realizou uma ideia, a qual no entanto tem como pressuposto uma certa inesgotabilidade dos meios materiais. Um Império dos Sonhos deveria ser fundado! - O caso é complicado, serei sucinto.

Primeiramente, foi adquirida uma região apropriada de três mil quilômetros quadrados. Um terço deste país é bem montanhoso, o resto é formado por uma planície e uma extensão de colinas. Grandes florestas, um lago e um rio dividem e dão vida a este pequeno império. Uma cidade foi fundada, vilarejos, fazendas arrendadas; houve uma necessidade imediata disso, pois já as primeiras povoações chegavam a doze mil almas. Agora o Império dos Sonhos conta sessenta e cinco mil habitantes. 
O desconhecido fez uma pequena pausa e tomou um gole de chá. Eu estava bem quieto e disse bastante perplexo:

- Continue!

E tomei conhecimento do seguinte:

- Patera tem extrema e profunda aversão a tudo que esteja vinculado ao progresso em geral. Digo mais uma vez, a tudo que esteja vinculado ao progresso, particularmente à área científica. Favor tomar minhas palavras aqui preferivelmente ao pé da letra, pois nelas reside o pensamento principal do Império dos Sonhos. O Império é separado do seu entorno por uma muralha de circunvalação e é protegido por construções robustas contra qualquer assalto. Um único portão permite entrar e sair, tornando fácil o mais rigoroso controle sobre pessoas e cargas. No Império dos Sonhos, refúgio para os insatisfeitos com a cultura moderna, tudo já foi providenciado para as necessidades físicas. O soberano deste país está longe de querer criar uma utopia, uma espécie de Estado do futuro. Necessidades materiais contínuas, diga-se de passagem, lá não existem. Os objetivos mais nobres desta comunidade estão acima de tudo menos voltados para a conservação dos valores reais, da comunidade e dos indivíduos. Não, nada disso! ... Mas vejo o senhor sorrindo incrédulo e de fato é quase demasiado difícil para mim descrever com simples palavras o que Patera de fato pretende com o Império dos Sonhos.

Primeiramente, cabe observar que toda pessoa que é admitida conosco, é predestinada para isso, seja por nascimento ou mais tarde pela sorte. É de conhecimento geral que órgãos dos sentidos eminentemente aguçados capacitam seus detentores para a compreensão de relações do mundo individual, as quais simplesmente não existem para seres comuns, exceto em alguns momentos isolados. E veja o senhor que justamente estas, digamos, coisas inexistentes constituem a essência principal das nossas ambições. No derradeiro e mais profundo sentido é o impenetrável fundamento do mundo que as pessoas dos sonhos, como elas se denominam, não descuidam sequer um instante. Talvez a vida normal e o mundo dos sonhos sejam opostos e justamente esta diferença torna a compreensão tão difícil. Quanto à pergunta: o que acontece de fato no país dos sonhos? Como se vive lá? Eu teria simplesmente que me calar. Eu poderia apenas lhe descrever a superfície, mas o que faz parte da essência do 
Homem dos sonhos é o fato de ele ambicionar a profundidade. Tudo é ancorado numa vida de preferência espiritualizada; alegria e sofrimento dos contemporâneos são estranhos ao sonhador e naturalmente que devem lhe permanecer estranhos por este ter uma escala de valores completamente diferente. O conceito de "estado de ânimo" é o que mais deveria aproximar-se do cerne da nossa questão, ao menos relativamente. Nosso pessoal vivencia apenas estados de ânimo, ou melhor, vive somente em estados de ânimo. Todo o ser exterior, o qual eles formam de preferência mediante colaboração complementar e de acordo com o desejo, fornece em certa medida apenas a matéria-prima. Para que esta não se esgote, obviamente providenciaram tudo de maneira pródiga. Mas o sonhador não crê em outra coisa senão no sonho, em seu sonho. Este é cultivado e desenvolvido entre nós; perturbá-lo seria um crime impensável de lesa-pátria. Daí também o rigoroso exame das pessoas que são convidadas a participar desta comunidade. Para ser breve e finalizar" - Aqui Gautsch afastou seu cigarro e me encarou calmamente:

“Claus Patera, senhor absoluto do Império dos Sonhos, contratou-me como emissário para entregar-lhe o convite de emigração para o país dele."

Minha visita pronunciou as últimas palavras um pouco alto e com bastante formalidade. Então, a criatura se calou e eu também fiquei primeiramente quieto, o que qualquer um dos meus leitores entenderá. De maneira quase compulsiva se me impusera nomeadamente o pensamento de estar sentado em frente a um doido. Para mim era deveras difícil dissimular minha inquietação. Assim como quem não quer nada, afastei a luz da proximidade da minha visita, ao mesmo tempo afastei jeitosamente um compasso e um pequeno estilete - objetos pontiagudos e perigosos.

Toda a situação era de fato altamente embaraçosa. No início da história do sonho pensei que se tratasse de uma brincadeira que algum conhecido pretendia fazer comigo. Infelizmente, este raio de esperança foi desaparecendo cada vez mais; e faz dez minutos que estou pensando obstinadamente sobre minhas chances. Por um lado, eu sabia que com doentes mentais o melhor é consentir nas ideias fixas. Mas mesmo assim! Não 
sou absolutamente nenhum gigante, sou uma pessoa tímida, no fundo frágil! E aí está sentado esse pesado Gautsch na minha sala, com fisionomia correta de alto funcionário público, pincenê e cavanhaque loiro.

Assim eram mais ou menos meus pensamentos naquela época. Também tinha de dizer alguma coisa, pois era o que meu interlocutor estava esperando. Havendo um acesso de raiva, no pior dos casos eu poderia apagar a lamparina e furtar-me discretamente daquele cômodo que me era bem conhecido.

“Certamente, certamente! Estou entusiasmado! Vou apenas consultar minha mulher. Amanhã, senhor Gautsch, o senhor receberá minha resposta." Falei em um tom tranquilo e me levantei. Meu convidado permaneceu calmamente sentado e disse secamente:

“O senhor está entendendo mal nossa atual situação, mas acho compreensível. É altamente provável que o senhor não me dê crédito, se é que sua inquietação contida com dificuldade não indique uma suspeita ainda maior em relação a mim. Asseguro-lhe, estou completamente são, são como qualquer um. O que lhe comuniquei é totalmente sério; que soe estranho, maravilhoso, isso eu tenho de admitir. Talvez o senhor fique mais calmo, tão logo o senhor tenha visto isto."

E nisso ele tirou um pequeno pacote e colocou-o na minha frente, em cima da mesa. Li meu endereço exato, removi o lacre e segurei nas mãos um estojo de couro liso de cor verde cinzenta. Dentro encontrava-se uma pequena miniatura, um busto bem característico de um homem jovem. Cachos castanhos emolduravam um semblante de característica estranhamente clássica; grandes, extremamente claros, diretamente da imagem me fitavam aqueles olhos: era inegavelmente Claus Patera...! Nesses vinte anos em que não nos víramos mais, eu não pensara sequer uma vez nesse colega de escola que considerava desaparecido. A visão de seu tão fiel retrato abreviou na minha mente aquele considerável lapso de tempo. Diante de mim surgiam os longos corredores amarelos do liceu de Salzburg, via novamente o antigo bedel com seu bócio congenial, mal disfarçado pelo refinado hábito de usar barba. Via-me outra vez entre os garotos e no meio deles também Claus Patera, humilhado com uma cartola de feltro, peça obrigatória de seu vestuário e oriunda do gosto duvidoso da tia que o criava. 
- De onde o senhor tirou esta imagem? Perguntei espontaneamente e tomado de um ânimo alegre e curioso. (...)

\section{Referências}

KUBIN, Alfred. Die andere Seite. [O outro lado] Frankfurt am Main: Suhrkamp, 2009.

RUTHNER, Clemens. Traumreich, die fantastische Allegorie der Habsburger Monarchie in Alfred Kubins Roman Die andere Seite (1908/09). Disponível em: <http://www.kakanien.ac.at/beitr/fallstudie/ CRuthner4.pdf> Acesso em 13 maio 2010. 